\title{
Educação Superior e formação humana: um diálogo com Pedro Goergen
}

\section{Resumo}

O presente trabalho leva adiante uma reflexão sobre educação superior e formação humana, mostrando que eles se encontram profundamente imbricados no pensamento de Pedro Goergen. Pretende-se mostrar como o conceito de formação humana constitui a base normativa de suas reflexões sobre a educação e, especificamente, sobre o ensino superior. Por essa razão, parte-se do diagnóstico de Goergen sobre o ensino superior e recorre-se ao seu conceito de formação humana para reconstruir o modo como ele o ancora na tradição filosófica e pedagógica ocidental e, sobretudo, na teoria social crítica contemporânea.

Palavras-chave: Educação superior; Formação humana; Pedro Goergen.

\section{Resumen}

Este trabajo lleva a cabo una reflexión acerca de la educación superior y formación humana, demostrando que las dos están conectadas en el pensamiento de Pedro Goergen. Se objetiva mostrar como el concepto de formación humana constituye la base normativa de sus reflexiones sobre la educación y, de manera específica, acerca de la enseñanza superior. Así, se parte del diagnóstico de Goergen sobre la enseñanza superior y se recurre a su concepto de formación humana para reconstruir la manera como él se ancla en la tradición filosófica y pedagógica occidental y, sobretodo, en la teoría social crítica contemporánea.

Palabras-clave: Educación superior; Formación humana; Pedro Goergen.

Filosofia e Educação [RFE] - Volume 8, Número 2 - Campinas, SP Junho-Setembro de 2016 - ISSN 1984-9605 - p. 141-167 
Ora, uma das experiências fundamentais da vida de qualquer pessoa é a sua educação. Para ela convergem e nela são elaboradas $e$ interpretadas as experiências no horizonte de uma biografia que é tecida com as demais biografias no contexto do mundo da vida.

Pedro Goergen (2008, p. 70)

\section{Considerações iniciais}

$\mathbf{P}$ edro Goergen tem se destacado, em mais de três décadas de trabalho acadêmico, por formar novas gerações com uma preocupação humanista singular que marca sua intervenção acadêmica. Desse modo, não se nega a dar sua contribuição, quando solicitado, aos mais diferentes espaços acadêmicos, como em diferentes Grupos de Trabalho (GTs) da Anped, especialmente ao GT Filosofia da Educação, no qual tem tido presença assídua. Também tem se envolvido com eventos nacionais e internacionais na área da educação ${ }^{1}$. Além disso, presta trabalho qualificado de consultoria a órgãos governamentais nacionais e internacionais de educação, especialmente a Secretarias Municipais, Estaduais e, diretamente, ao Ministério de Educação do governo brasileiro. Mais recentemente, contribuiu de modo significativo, como consultor, na elaboração e implantação do curso de doutorado em educação da Universidade de Passo Fundo (UPF), registrando-se que um dos eixos temáticos do referido curso consiste na investigação da formação humana em sociedades plurais marcadas por formas pós-metafísicas de pensamento $^{2}$.

1 A título de exemplo, tem participado como conferencista em todas as quatro edicões do Seminário Internacional sobre Filosofia e Educação, realizadas na UPF (Passo Fundo, RS), desde 2003, e nas duas edições da Reunião Científica sobre Teoria Critica e Educação, ocorridas na UNCPBA, campus de Tandil, Argentina.

2 Essa temática põe, entre outros, o desafio de assegurar as diferenças individuais e de grupo em um mundo globalizado. Encontramos essa preocupação na seguinte passagem do texto de Goergen: "Trata-se, sobretudo, de levar em consideração o contexto do mundo globalizado, interdependente e interconectado, sem esquecer a exigência de reconhecimento

Filosofia e Educação [RFE] - Volume 8, Número 2 - Campinas, SP Junho-Setembro de 2016 - ISSN 1984-9605 - p. 141-167 
Como não bastasse o envolvimento com todas essas atividades, Goergen tem se destacado, também, pela produção científica tanto na forma de livro como de artigos em periódicos, abrangendo uma grande amplitude temática e abordando, simultaneamente, vários problemas do campo educacional. Sua intensa e diversificada produção científica encontra o fio condutor em dois temas específicos, a saber, no ensino superior e na formação humana, cruzando-se mutuamente entre si. Ora, é tal cruzamento que o permite estabelecer o diálogo permanente entre políticas educacionais e filosofia da educação ${ }^{3}$, pensando uma em estreita sintonia com a outra.

Na sequência, como forma de prestar homenagem ao seu trabalho acadêmico, gostaríamos de refletir sobre estes dois temas, educação superior e formação humana, mostrando que eles se encontram profundamente imbricados no pensamento de Goergen. Ou seja, pretendemos mostrar, mais precisamente, como o conceito de formação humana constitui a base

das identidades e diferenças individuais e grupais" (2008, p. 42). Somente uma ideia de educação baseada na cidadania democrática forma pessoas com mente alargada, capazes de reconhecer pontos de vista diferentes e conviver com eles.

3 Os pensamentos de Goergen sobre filosofia da educação têm como eixo articulador a ideia de formação humana, embora não se esgotem nela. Ele tem dedicado vários ensaios para tratar do tema, especialmente, em "Questões impertinentes para a Filosofia da Educação" (2006, p. 589-606), no qual busca defini-la, também, delineando suas principais tarefas no contexto do debate entre modernos e pós-modernos. A filosofia da educação precisa, segundo ele, levar a sério os questionamentos feitos sobre o sentido da história, do sujeito e dos valores, analisando, com auxílio do questionamento pós-moderno, os limites intrínsecos aos ideais iluministas, sem, contudo, promover uma despedida apressada da modernidade. Se, por um lado, não podemos mais aceitar uma razão totalizante e dogmática que culminou nas experiências catastróficas do século $\mathrm{XX}$, por outro, não podemos concordar com a crítica ao iluminismo que desemboca no individualismo irresponsável. A filosofia da educação teria a tarefa de continuar perguntando pelo sentido do aspecto formativo educacional humano, mas não mais com base na noção forte de fundamentação e nem mais na defesa de uma subjetividade transcendental, como ocorreu em grande parte da tradição iluminista moderna. Para Goergen, a filosofia da educação possui, então, a tarefa de "reconstruir uma nova base dialógica como estratégia de validação de princípios educacionais" (2006, p. 604), evitando, com isso, o extremismo de qualquer direção, quer seja ao dogmatismo inerente ao modo moderno de fundamentação, quer ao relativismo inaceitável que brota de alguns círculos do pensamento pós-moderno que pretendem abrir mão de qualquer tipo de fundamentação.

Filosofia e Educação [RFE] - Volume 8, Número 2 - Campinas, SP

Junho-Setembro de 2016 - ISSN 1984-9605 - p. 141-167 
normativa de suas reflexões sobre a educação e, especificamente, sobre o ensino superior.

Vamos desenvolver nossa "hipótese de trabalho" partindo do diagnóstico que Goergen faz do ensino superior. Na sequência, recorremos ao seu conceito de formação humana, reconstruindo o modo como ele o escava na tradição filosófica e pedagógica ocidental, retendo dela o que julga atual para pensar os rumos da educação superior. $O$ leitor familiarizado com sua produção científica logo perceberá que delimitamos nossa abordagem, principalmente, em dois de seus trabalhos mais recentes: "Educação superior na perspectiva do Sistema e do Plano Nacional de Educação" (2011) e "Formação ontem e hoje" (2009).

\section{Diagnóstico atual da educação superior}

A preocupação de Goergen com a perda crescente de autonomia do ensino superior e a sujeição progressiva do sistema educacional às tendências tecnicistas da sociedade global de mercado e aos seus organismos internacionais de financiamento da educação não é exclusividade só de seu pensamento, pois dela tomam parte, também, outros autores internacionais, entre os quais Martha Nussbaum, nos Estados Unidos, e Reinhardt Brandt, na Alemanha. No âmago dessa preocupação está o reducionismo na formação profissional das novas gerações, as quais, ao se concentrarem cada vez mais no domínio técnico altamente especializado, não são estimuladas a desenvolver a capacidade para conviver com culturas estranhas e a respeitar pontos de vista diferentes. Como se pode observar, o que está em jogo, quando predomina a tendência tecnicista e mercadológica como diretriz da educação, é o risco iminente de uma formação não mais voltada à democracia, compreendida como forma de vida humana mais apropriada às sociedades plurais.

Filosofia e Educação [RFE] - Volume 8, Número 2 - Campinas, SP Junho-Setembro de 2016 - ISSN 1984-9605 - p. 141-167 
Vamos resumir, primeiro, como Nussbaum e Brandt caracterizam, respectivamente, os cenários americano e alemão, para, em seguida, expor o diagnóstico de Goergen sobre o cenário brasileiro do ensino superior. Com isso, podemos observar que as profundas transformações que começam a ocorrer no ensino superior brasileiro, sobretudo, nas duas últimas décadas, de modo algum configuram mu danças isoladas, uma vez que se inserem no panorama internacional, sendo, em certa medida, seu reflexo.

Em um estudo recentemente publicado, Nussbaum $(2010)^{4}$ manifesta sua preocupação sobre os rumos que o ensino superior americano está tomando. No núcleo de seu diagnóstico, encontra-se a tese de que as universidades americanas estão excluindo cada vez mais dos currículos de seus cursos as disciplinas humanistas, entre as quais literatura, filosofia, história e artes. Mas o que está na base dessa tendência, impulsionando-a? Segundo Nussbaum, há uma tendência mundial de sujeição dos países, com seus respectivos sistemas educacionais, às orientações do mercado global, assumindo quase irrestritamente a lógica do crescimento econômico e adotando como norma exclusiva uma educação voltada para a obtenção do lucro.

A referida autora destaca, como característica central do modelo de desenvolvimento econômico adotado pelo mercado global atual, o investimento financeiro maior nas áreas técnico-científicas e a redução de investimento nas áreas humanas e sociais. Ora, a educação pensada segundo esse "velho" paradigma do desenvolvimento econômico apresenta, também, características bem definidas:

a) Requer, como aptidões básicas, a alfabetização e a competência matemática, fazendo que o currículo se centre exclusivamente nessas duas áreas, tornando marginais ou secundárias as demais.

4 Faremos uma reconstrução livre de algumas de suas principais ideias, do mesmo modo como procederemos, na sequência, com Brandt.

Filosofia e Educação [RFE] - Volume 8, Número 2 - Campinas, SP Junho-Setembro de 2016 - ISSN 1984-9605 - p. 141-167 
b) Deposita otimismo exagerado nos novos dispositivos tecnológicos digitais, tendendo a reduzir o sentido amplo de educação ao ensino informatizado. Com isso, prioriza a introdução massiva dos dispositivos tecnológicos educacionais nas instituições de ensino, sem dar a necessária ênfase à preparação pedagógica dos professores. Também não dá devida atenção à criação dos cenários pedagógicos adequados para que se possa fazer um bom uso das novas tecnologias de informação.

c) O referido paradigma dificilmente se ocupa com o problema da desigualdade do acesso ao ensino superior, tomando a questão da ampliação somente pela ótica da maximização do lucro e da redução dos investimentos financeiros direcionados à educação. Poderíamos acrescentar que, no caso brasileiro, esse problema se torna ainda mais sintomático, tendo-se em mente o nível de investimento por aluno e professor, nos diferentes níveis do sistema de ensino, quando comparado com índices de outros países.

d) Por fim, outro aspecto do referido paradigma é o silêncio quase absoluto em relação ao problema crucial da distribuição nacional e mundial da renda. Ou seja, o mercado global coloca o desenvolvimento econômico de cada país como dependente do investimento na educação, mas favorece cada vez mais a enorme concentração da riqueza em mãos privadas, a qual dificulta o próprio financiamento público da educação.

Em síntese, o paradigma do desenvolvimento econômico requer uma noção cada vez mais tecnicista e instrumental de educação, que seja capaz de se adaptar eficazmente ao mercado global e não oponha resistência ao crescente processo de acumulação de riqueza, fechando os olhos ao problema da justa distribuição de renda. Para Nussbaum, um modelo de 
desenvolvimento humano, sustentado por uma ampla e diversificada tradição pedagógica, seria um aspecto importante do amplo movimento de crítica ao predomínio do paradigma do desenvolvimento econômico. $\mathrm{Ou}$ seja, o resgate crítico de ideias pedagógicas formuladas por autores como Rousseau, Froebel, Pestalozzi, Montessori, Piaget, Dewey e outros, estaria na base de sustentação de um conceito ampliado de educação considerado indispensável para justificar a formação profissional alargada.

Esse conceito ampliado de educação preservaria, no seu núcleo, entre outros, os seguintes ideais pedagógicos: a) o educando enquanto sujeito ativo da aprendizagem; b) a formação do pensamento crítico baseada no autoexame permanente dos envolvidos no processo pedagógico; c) o desenvolvimento da imaginação empática capaz de incluir em seu modo de pensar e agir a perspectiva do outro; e d) por fim, a formação para a cidadania universal que possa promover o sentimento de pertença à humanidade, e não somente a uma etnia, grupo ou nacionalidade.

Portanto, segundo Nussbaum, no bojo desse conceito amplo de educação, estaria o compromisso inalienável de cada ser humano e, especialmente, das instituições de ensino, com a democracia e a humanidade. Pensado nesses termos, a educação seria muito mais do que o mero ensino profissionalizante, transformando-se num amplo processo de formação cultural, dando origem a um profissional com mente alargada. Ora, tal profissional, além da competência técnica necessária, também disporia da capacidade de imaginação empática, indispensável para tomar o outro não como objeto, mas sim como pessoa digna de valor.

Muitas das preocupações de Nussbaum são formuladas, em vocabulário próprio, por Brandt (2011), ao diagnosticar criticamente a situação da universidade alemã, depois de uma década de implantação rigorosa das principais diretrizes da Declaração de Bolonha. O núcleo de seu diagnóstico enfatiza a introdução, no sistema do ensino superior, do modelo

Filosofia e Educação [RFE] - Volume 8, Número 2 - Campinas, SP Junho-Setembro de 2016 - ISSN 1984-9605 - p. 141-167 
de gerenciamento empresarial, baseado em técnicas modernas de gestão. Tal introdução provoca, como um de seus efeitos colaterais negativos, a redução da noção de conhecimento ao saber técnico, cada vez mais restrito ao manuseio instrumental de informações momentaneamente úteis e aplicáveis. Nesse caso, o que Nussbaum denunciou como negação do conceito amplo de educação, Brandt formula aqui, no contexto acadêmico alemão, como redução do conhecimento ao saber técnico. O que se perde, em ambos os casos, é a formação humana na perspectiva de uma mente alargada capaz de viver num mundo cada vez mais plural, com a capacidade de se sentir genuinamente interessado pelos demais (imaginação empática). Como essa distinção entre conhecimento e saber técnico é decisivo para compreender o diagnóstico de Brandt, precisamos reconstruí-la brevemente.

Brandt reserva ao termo "conhecimento" (Erkenntinis) toda a potencialidade crítica do pensamento, dinamizada pela capacidade de pensar por si mesmo, de tomar posição de modo autônomo e de se responsabilizar pelos seus atos. Nesse sentido, investido pela posição do conhecimento, o ser humano coloca-se mediante uma norma moral e sente-se obrigado a prestar contas a outras pessoas que podem exigir as razões de suas posições e atitudes. O que é fundamental nessa definição de conhecimento, para o contexto acadêmico, é que ela surge da contraposição ou disputa entre investigadores da comunidade científica e, com isso, está aberta à crítica ${ }^{5}$.

O saber (Wissen) técnico, por sua vez, é adquirido no dia a dia, ou em instituições particulares. Não precisa de fundamentação alguma, pois se preserva a si mesmo e encontra legitimidade na força de poder ser utilizado imediata e pragmaticamente. Enquanto esse tipo de saber pode ser

5 Isso justifica, então, porque a racionalidade processual e falibilista, crítica à racionalidade dogmática, é mais apropriada para dar conta dos problemas que emergem das sociedades plurais e complexas, marcadas por formas pós-metafísicas de pensamento. Sobre a importância da racionalidade falibilista como contraposição às diferentes formas de fundamentalismo contemporâneo, ver o livro de Bernstein (2006).

Filosofia e Educação [RFE] - Volume 8, Número 2 - Campinas, SP Junho-Setembro de 2016 - ISSN 1984-9605 - p. 141-167 
acumulado, quantificado e medido, o conhecimento repousa sobre atividade própria e está imune à possibilidade de ser quantificado (BRANDT, 2011, p. 9). Ou seja, essa distinção de Brandt pressupõe que a racionalidade do conhecimento, como está sujeito à crítica, abre-se à possibilidade de ser modificado, ou, até, de abandonar suas premissas refutadas. $\mathrm{O}$ mesmo não ocorre com o saber técnico, o qual, estando mais vulnerável ao dogmatismo, vê-se impedido de revisar, permanente e adequadamente, seu próprio ponto de vista ${ }^{6}$.

Com base na distinção entre conhecimento e saber técnico, Brandt formula a tese de que as universidades são instituições reais do conhecimento, e não números planificados do saber profissionalizante. Voltando-se contra as diretrizes das políticas educacionais públicas da Alemanha, ele afirma:

Pois, o cosmopolitismo do conhecimento é uma coisa do mundo acadêmico livre, e não da burocracia com seus respectivos ministros e ministras. Os primeiros cosmopolitas foram os antigos filósofos, e não pessoas da burocracia local, alemã ou europeia, com decretos e regras de medida na cabeça (BRANDT, 2011, p. 11-12).

Desse modo, fora reservado às universidades, e não simplesmente às escolas superiores ou às faculdades, o lugar para o desenvolvimento das mais diversas atividades focadas na produção e socialização do conhecimento. Ora, o que a Declaração de Bolonha fez foi eliminar a diferença entre universidade e centros de ensino superior e faculdades,

6 Brandt tem em mente, aqui, certamente aquele tipo de saber técnico especializado que está na base da formação profissionalizante rápida, voltada à qualificação da força de trabalho para o mercado. Não deve ser confundido, portanto, com a noção de saber como modo próprio de existência que não se deixa determinar exclusivamente pelo modus operandi da ciência e da técnica modernas.

Filosofia e Educação [RFE] - Volume 8, Número 2 - Campinas, SP Junho-Setembro de 2016 - ISSN 1984-9605 - p. 141-167 
ressaltando sobremaneira a noção de saber-gerencial (Wissens-Management) em detrimento do conceito de conhecimento.

Esse resumo esquemático já é suficiente para termos uma ideia geral sobre algumas tendências mundiais do ensino superior, representadas aqui, paradigmaticamente, pelos casos americano e alemão. E o que acontece no cenário brasileiro? Como Goergen nos auxilia a pensá-lo? Sua análise ajudanos, antes de tudo, a tornar mais claros muitos argumentos e intuições subjacentes à posição tanto de Nussbaum como de Brandt, sobretudo porque estabelece, de modo mais nítido, o vínculo entre economia global de mercado e o ensino superior. Ou seja, Goergen é claro quando indica a tendência economicista subjacente à globalização mundial, considerando que é ela que na prática determina "os rumos da sociedade contemporânea em todas as suas dimensões" (GOERGEN, 2010, p. 898).

Cabe-nos perguntar, então, como essa tendência global economicista interfere especificamente no ensino superior? Para Goergen, ela impõe duas novas exigências ao ensino superior: em primeiro lugar, torna muito mais explícito e enfático o valor econômico do conhecimento, do qual passa a ser interessante somente sua dimensão utilitária e instrumental. Isto é, o que interessa do conhecimento nessa condição é, em última instância, seu aspecto rentável e lucrativo. Desse fio condutor geral, desprende-se o status dado a esta ou àquela profissão e, também, o lugar ocupado por esta ou aquela área de conhecimento ou disciplina na organização curricular. Desse modo, com sua própria terminologia, Goergen está indicando aqui o mesmo fenômeno constatado por Brandt na Alemanha, da redução do conhecimento ao saber técnico e, de outra parte, por Nussbaum, nos Estados Unidos, da educação voltada ao lucro e à renda, com foco na especialização técnica, em detrimento da formação humanista.

Em segundo lugar, Goergen torna evidente em sua análise o quanto a universidade, como lugar de produção e socialização do conhecimento, Filosofia e Educação [RFE] - Volume 8, Número 2 - Campinas, SP Junho-Setembro de 2016 - ISSN 1984-9605 - p. 141-167 
torna-se um ponto estratégico à própria produção dessa nova noção de conhecimento como valor mercadológico e aplicável. Ou seja, o ensino superior assumiu uma dimensão econômica manifesta, principalmente nessas duas últimas décadas, devido à sua relação particular com a produção de certos conhecimentos vinculados diretamente com o desenvolvimento econômico industrial. Segundo Goergen:

Como produtora de conhecimento, hoje matéria-prima dos processos produtivos, a universidade, envolvida pelos tentáculos da economia, tende, no limite, a transformar-se em prestadora de serviços, sujeita às regras do mercado, comandado pelas corporações transnacionais (2010, p. 900).

Como o sistema de produção precisa da inovação e da criação tecnológica permanente e como, por várias razões, entre as quais a da redução de custos, não assume tal inovação em seu próprio interior, recorre a parcerias com as universidades por meio do financiamento público estatal.

O caso mais recente desse fenômeno, a título de ilustração, é a implantação de parques tecnológicos no interior de universidades particulares e de fundações de ensino. Isso configura a parceria triparte entre universidade, Estado e empresa, visando à inovação e criação tecnológica, concebida, certamente, como estratégia de desenvolvimento do conhecimento tecnológico (saber técnico) para atender às demandas do novo sistema produtivo baseado no domínio de informações. Isso mostra, entre outras coisas, que a universidade, como lugar de produção do conhecimento, transforma-se rapidamente no espaço apropriado para a elaboração de saberes e tecnologias estratégicas ao novo sistema de produção. Contudo, o que essa nova forma de parceria significa em termos de estímulo à pesquisa e à própria formação profissional no interior dessas universidades e o quanto 
ela desenvolve ou compromete a autonomia da pesquisa e da própria produção do conhecimento é algo ainda a ser percebido. De qualquer forma, um projeto amplo de universidade que possua como diretriz a formação profissional alargada precisa ficar atento ao possível reducionismo da noção de conhecimento ao saber técnico útil e aplicável e à consequente perda de autonomia da pesquisa. Outra tendência indicada por Goergen, em sua análise, é aquela que, originando-se do "Consenso de Washington" (1989), reduz o papel do Estado a tarefas educativas, atribuindo-lhe a educação básica como responsabilidade e delegando o ensino superior ao mercado. A consequência negativa desse processo é indicada por ele com as seguintes palavras:

$\mathrm{O}$ resultado foi o ingresso de algumas universidades na bolsa de valores, a criação de corporações acadêmicas supranacionais gestadas a partir de suas sedes nos países desenvolvidos, a organização de grandes redes internacionais de educação a distância e, sobretudo, a crescente transformação da educação em mercadoria ao encargo de empresas privadas interessadas no lucro (GOERGEN, 2010, p. 900).

Todo esse movimento foi amparado pelos organismos financeiros internacionais, sob a liderança destacada do Banco Mundial, o qual desempenhou papel importante na execução das metas de transformar a educação em uma alavanca do desenvolvimento econômico, principalmente em países como o Brasil. Mas a liderança do Banco Mundial não foi só econômica, senão também intelectual e política, no sentido de fortalecer a ideia da educação como um "bem não estritamente público", para, em seguida, a partir desse entendimento, defender abertamente a competitividade, o financiamento alternativo e a própria privatização do ensino superior.

Filosofia e Educação [RFE] - Volume 8, Número 2 - Campinas, SP Junho-Setembro de 2016 - ISSN 1984-9605 - p. 141-167 
As preocupações de Goergen (2012) alcançam, também, a pósgraduação e seu processo de internacionalização. $\mathrm{O}$ autor chama a atenção para a influência de forças supranacionais que não podem ser desconsideradas no que diz respeito à internacionalização das Instituições de Ensino Superior e da pós-graduação, forças muitas vezes fomentadas por interesses divergentes e contraditórios, sobretudo de ordem econômica. É claro que a internacionalização é um "fenômeno incontornável", motivo pela qual o ponto não é internacionalizar ou não a pós-graduação, mas definir que internacionalização pretende-se levar adiante. Prova dessa incontornabilidade são os grandes desafios que se configuram como problemas globalizados e afetam a humanidade como um todo, razão pela qual muitos deles só podem ser administrados ou resolvidos mediante um esforço conjunto de investigação e de ação entre vários países ${ }^{7}$. Além disso, do ponto de vista das IES propriamente ditas, o processo de globalização trouxe desafios importantes, tais como incrementar a produção e a difusão do conhecimento e ampliar o intercâmbio de estudantes e docentes.

Goergen (2012, p. 253) chama a atenção para duas abordagens sobre a internacionalização no campo da educação. A primeira concerne à imposição de um padrão de relativa homogeneização dos sistemas de ensino e das políticas de educação nacionais dirigido por interesses moldados por forças supranacionais e seus imperativos econômicos. Essa abordagem pode ser ilustrada pela Declaração de Bolonha e pela homogeneização dos currículos que dela decorre. Tal abordagem seria o reflexo da aplicação de dispositivos econômicos a serviço da ordem econômica internacional, e a adaptação a ela dar-se-ia pela força da pressão econômico-política. A segunda abordagem diz respeito ao fato de haver um interesse, oriundo de

7 Esse alerta já era feito pelo filósofo Karl-Otto Apel (1999) no final da década de 60 e início dos anos 70, o que o levou a formular uma abordagem denominada "Ética da responsabilidade na era da ciência". Naquela época ele se referia, sobretudo, à problemática do meio ambiente e à questão do arsenal de armas nucleares (contexto da Guerra Fria).

Filosofia e Educação [RFE] - Volume 8, Número 2 - Campinas, SP Junho-Setembro de 2016 - ISSN 1984-9605 - p. 141-167 
diferentes países, em modernizar os sistemas educacionais, e esse fator seria responsável pela abertura desses sistemas a um padrão internacional de políticas educacionais. A internacionalização aqui seria entendida como decorrente da cultura ocidental, baseada em valores e estratégias políticoeconômicas que invadem a vida moderna e, logo, os sistemas educacionais. Nesse caso, a adesão à internacionalização dar-se-ia em razão do interesse de cada país em integrar-se internacionalmente.

A primeira abordagem retrataria uma forma mais sofisticada de continuidade do colonialismo acadêmico da primeira metade do século XX, mediante o qual ocorreu a exportação de modelos educacionais para os países periféricos, visando à modernização destes, por países como Estados Unidos, Alemanha e Inglaterra (DE WITT, 2002). A internacionalização poderia ser pensada, todavia, no contexto de países latino-americanos, mais no sentido ativo de cooperação e de integração do que vinculada ao modelo de uma abertura subordinada a forças supranacionais.

Em síntese, o que está em jogo, nesse amplo contexto de economia global de mercado, é a dupla transformação: primeiro, do conhecimento em fator de produção, considerado como valor econômico, e, segundo, da educação em empresa provedora desse tipo de conhecimento. $\mathrm{O}$ resultado disso foi, em última instância, a redução da educação ao saber técnico e à "formação de profissionais adaptados e úteis ao mercado" (Consenso de Washington, 1989) .

Ao voltar-se para o ensino superior brasileiro, Goergen faz seu diagnóstico da situação atual ser acompanhado pela expectativa otimista em

8 Em outro ensaio, Goergen manifesta-se sobre a situação do conhecimento na economia global de mercado do seguinte modo: “A legitimação que passa a prevalecer é a lógica do mercado e, portanto, do lucro. Distanciada do social e abandonada pelo Estado, não resta alternativa à produção do conhecimento senão adequar-se aos interesses e imposições do mercado. O maior compromisso da comunidade científica deixa de ser com o bem público, ou seja, com o bem-estar social, mas com o mercado, isto é, com os potenciais clientes/consumidores privados e seus interesses" (GOERGEN, 2014, p. 494).

Filosofia e Educação [RFE] - Volume 8, Número 2 - Campinas, SP Junho-Setembro de 2016 - ISSN 1984-9605 - p. 141-167 
relação ao papel que a Conferência Nacional de Educação (Conae, 2010), tanto na condição de movimento político como na de documento subsidiário, pode desempenhar na formulação e execução de políticas educacionais públicas favoráveis aos anseios da população brasileira. De seu diagnóstico sobre o ensino superior brasileiro cabe destacar, como quadro desalentador e, por isso, exigente de medidas governamentais urgentes, o fato de termos apenas $13 \%$ dos jovens entre 18 e 24 anos frequentando o ensino superior. De outra parte, o Brasil apresenta, nesse contexto, um dos sistemas de educação mais mercantilizados do mundo: $73 \%$ das matrículas e $90 \%$ das instituições são do setor privado 9 .

Considerando esse cenário frágil do ensino superior brasileiro, Goergen reforça a necessidade do engajamento da sociedade e do Estado na construção de um Sistema e de um Plano Nacional de Educação. Defende a gestão democrática das instituições como princípio constitucional que deve orientar a busca do ensino público gratuito, universal e de qualidade. Ora, esse é justamente um dos aspectos destacados pelo próprio documento da Conae, o qual, por ser ele próprio resultado de deliberação coletiva, deveria, aos olhos de Goergen, ser respeitado, servindo de referência ao governo no estabelecimento de políticas educacionais públicas.

A defesa da educação com qualidade como um "bem público" e dever do Estado é acompanhada, na análise de Goergen ${ }^{10}$, pela ênfase na consolidação de um sistema nacional de avaliação, como um dos eixos centrais da política educacional. Ou seja, em sua compreensão, a almejada qualidade na educação não pode ser alcançada se não estiver amparada, também, por uma avaliação de qualidade, pois é ela que se torna um dos

9 Os dados apresentados acima correspondem a 2010, ano de publicação do ensaio de Goergen em análise.

10 Em outro ensaio, no qual discute o papel da educação na formação do espaço público democrático, Goergen volta a insistir na ideia da educação como um bem público, afirmando que sua dimensão política repousa, então, na "luta pela preservação da educação como bem público de responsabilidade do Estado democrático" (2008, p. 70).

Filosofia e Educação [RFE] - Volume 8, Número 2 - Campinas, SP Junho-Setembro de 2016 - ISSN 1984-9605 - p. 141-167 
principais mecanismos de ampliação do poder de controle e regulação do Estado. Além disso, a avaliação se torna uma ferramenta indispensável para promover mudanças na gestão, pesquisa, extensão e na própria formação profissional oferecida pelo ensino superior.

Portanto, ciente dos desafios que o ensino superior brasileiro apresenta, Goergen vê na Conae, como amplo movimento representado tanto pelas instituições de ensino, por movimentos sociais e pelo próprio poder público, uma oportunidade inigualável. Além disso, o autor apoia essa sua expectativa na noção de globalização assentada no sentido normativo de internacionalização como cooperação solidária entre os países. Ele se vê, assim, esperançoso com a possibilidade de se forjar um novo modelo de ensino superior, que possa corresponder às exigências dos novos tempos, sem se curvar ao reducionismo econômico da globalização mundial, entendida, nesse sentido, não como internacionalização, mas como transnacionalização $0^{11}$.

Sob esse aspecto, os rumos do desenvolvimento da sociedade internacional globalizada, quando não se deixam orientar exclusivamente pela dimensão economicista da globalização, parecem indicar para uma nova cultura universitária:

[...] a cultura da gestão estratégica e eficaz, da pertinência social e democrática, da informática e comunicação, da pesquisa, ensino e extensão, da qualidade e avaliação, da transdisciplinaridade e abertura internacional, enfim, da formação cidadã crítica e cultural (id., ibid.).

11 Goergen apoia-se no pensamento de Tünnermann Bernheim para fazer a distinção entre internacionalização e transnacionalização. Parafraseando-a, tal distinção repousa no seguinte: enquanto a transnacionalização prima pela cooperação dominadora, na medida em que facilita o estabelecimento nos países em desenvolvimento de filiais universitárias vinculadas a grandes empresas, com origem em países desenvolvidos, a internacionalização "luta por uma cooperação internacional solidária com ênfase na cooperação horizontal, baseada no diálogo intercultural e respeitoso da idiossincrasia e identidade dos países participantes" (BERNHEIM apud GOERGEN, 2010, p. 901).

Filosofia e Educação [RFE] - Volume 8, Número 2 - Campinas, SP Junho-Setembro de 2016 - ISSN 1984-9605 - p. 141-167 
Em síntese, para Goergen, o enfrentamento adequado dos inúmeros desafios inerentes ao ensino superior brasileiro passa, inevitavelmente, pela defesa firme da educação como um bem público e de dever do Estado, o qual possui compromisso de geri-la democraticamente. Portanto, bem público e gestão democrática constituem o núcleo de um conceito amplo de educação que deveria estar na base da reformulação e ampliação do ensino superior. Podemos nos perguntar agora: por que a educação é um bem público, de dever do Estado e a ser gerida democraticamente? Goergen busca justificá-lo com base no recurso ao conceito normativo de formação humana, isto é, por ser um fenômeno intrinsecamente humano é que a educação deve tornar-se um bem público e um dever do Estado. Ora, justamente aí é que repousa a profunda imbricação entre políticas educacionais e filosofia da educação em seu pensamento. Interessa-nos, na sequência, analisar o conteúdo normativo que Goergen atribui à noção de formação humana, pois só assim podemos compreender o que significa tomar a educação como um bem intrinsecamente humano.

\section{A ideia de formação humana}

Pensar os diversos e difíceis problemas que assolam a educação contemporânea, especialmente os desafios que estão postos ao ensino superior brasileiro, recorrendo à ideia de formação humana, pode tornar-se um procedimento altamente duvidoso, se não levar em consideração os diferentes motivos de pensamento pós-metafísico. Qualquer iniciativa empreendida hoje, por exemplo, no âmbito do pensamento político sobre a educação, que queira delinear políticas educacionais, recorrendo diretamente ao conceito de formação humana que é oferecido pela tradição, já estaria fadada ao fracasso se desconsiderasse as críticas que desde a 
modernidade são feitas ao conteúdo metafísico de tal conceito. De outra parte, também é preciso levar em consideração que tais críticas, ao menos aquelas feitas com adequação e seriedade filosófica, não fazem "tabula rasa" da tradição e, menos ainda, invalidam a ideia de formação humana como referência normativa para pensar os problemas educacionais atuais ${ }^{12}$.

Analisemos, agora, com mais cuidado e brevemente, a tendência atual, emergida da crítica ao conceito metafísico de formação, de negar a tradição como um todo. Tal tendência encontra sua fonte de inspiração no trabalho iniciado por Nietzsche, passando por Heidegger, até desembocar no trabalho criativo do último Foucault. Esses três autores, cada um a seu modo, apresentam argumentos suficientes para pôr em questão, por um lado, a noção de natureza e essência humana e, por outro, o aspecto teleológico (da tradição grega antiga) e o aspecto escatológico (da tradição medieval) que sustentou o conceito de formação humana. Contudo, a crítica desferida por esses três autores ao humanismo ocidental não culminou na negação em bloco da tradição e, menos ainda, da força normativa do pensamento, manifestado, por exemplo, na ideia do autoexame constante e do cuidado de si mesmo.

Nesse sentido, não seria muito difícil, por exemplo, recorrer aos últimos seminários de Foucault, proferidos no Collège de France pouco tempo antes de sua morte, para mostrar o modo criativo como dialoga com a

12 Nesse sentido, do mesmo modo como as noções de razão e de sujeito, a ideia de formação humana não pode mais ser pensada nos termos de uma metafísica da subjetividade que tem na noção de representação seu eixo articulador. Heidegger está entre os pensadores mais importantes do século XX que desferiu duro golpe à metafísica da subjetividade e à noção de formação humana a ela correspondente. É dele a afirmação bombástica de que a "época da formação se aproxima do fim" (HEIDEGGER, 2004, p. 59). Ele não está negando aqui a ideia de formação humana como um todo, mas sim, especificamente, da formação justificada pela "razão imutável”, baseada na pressuposição segura e inquestionável. Como grande pensador, Heidegger antecipou o problema, com o qual nos debatemos hoje, de como formar novas gerações num contexto social e cultural plural, que não pode mais contar com um único princípio ou núcleo de referência.

Filosofia e Educação [RFE] - Volume 8, Número 2 - Campinas, SP Junho-Setembro de 2016 - ISSN 1984-9605 - p. 141-167 
tradição grego-romana antiga ${ }^{13}$. Por meio desses seminários, também podemos ver o quanto a noção de cuidado de si assume papel normativo indispensável, mas não no sentido prescritivo, aos seus propósitos: tal conceito está na base de sua noção de filosofia como modo de vida e como estética da existência. Do cuidado de si brota, também, a crítica à pedagogia como transmissão de saber e a possibilidade de pensá-la como um saber de espiritualidade.

Se esses autores não promovem a despedida da tradição e preservam certa normatividade ao conceito de formação humana, então, o problema reside, em maior parte, no modo como eles são recebidos por setores do discurso pedagógico contemporâneo. Ao fazer uma leitura apressada desses autores, parte do discurso pedagógico contemporâneo ignora o próprio trabalho cuidadoso e demorado que eles fizeram da tradição intelectual passada. Tal leitura serve mais aos propósitos pedagógicos atuais de invalidar em bloco a chamada "pedagogia tradicional", reduzindo-a meramente à pedagogia da "transmissão" e da "memorização" de conteúdos e, com isso, abrindo mão dos ideais iluministas como um todo ${ }^{14}$. No bojo desse discurso, que seduz enormemente o professorado, encontra-se o esquecimento da pergunta pela validade do conhecimento pedagógico e, por conseguinte, da pergunta pelas bases epistemológicas e metodológicas da pesquisa em educação. Ao abrir mão do diálogo vivo com a tradição filosófica e ao focar na sua aproximação espontânea com a literatura, tal discurso provoca, simultaneamente, a diluição do conhecimento pedagógico

13 Sobre esse tema, ver a coletânea "Foucault y la filosofia antígua", organizada por Gros e Lévy (2004).

14 Foi o debate entre modernos e pós-modernos que se estendeu no continente europeu na década de 1980, sobretudo entre os franceses (Lyotard) e os alemães (Habermas), chegando ao Brasil na década seguinte, que impulsionou a crítica pós-moderna aos ideais iluministas. No artigo citado acima, Goergen (2006, p. 589-606) faz um balanço crítico desse debate, sem esconder sua simpatia teórica pela posição de Habermas.

Filosofia e Educação [RFE] - Volume 8, Número 2 - Campinas, SP Junho-Setembro de 2016 - ISSN 1984-9605 - p. 141-167 
no discurso apenas narrativo e metafórico dos problemas formativos nucleares da condição humana.

O resultado disso é a renúncia à pergunta sobre os critérios de validade que permitem tomar criticamente, por um lado, a experiência das gerações passadas como referência para pensar a formação das novas gerações e, por outro, compreender a própria experiência humana como experiência formativa de construção de um mundo em comum. Em síntese, a recusa do trabalho crítico interpretativo da tradição intelectual passada e o abrandamento da noção de educação como diálogo conflitivo entre gerações conduzem à flexibilização excessiva da noção de autoridade, inviabilizando, em última instância, a profunda noção de educação como responsabilidade pelo mundo (ARENDT, 1994).

Se a crítica necessária à tradição não a inviabiliza, nem conduz à negação da ideia de formação, como pensá-la a partir do contexto atual marcado por formas pós-metafísicas de pensamento? Que normatividade é possível assegurar à ideia de formação humana? Aprendemos, instrutivamente, com as diferentes formas pós-metafísicas de pensamentos que não se sustenta mais a noção de alma ou consciência como uma unidade substancial, inata ou transcendental, da qual emergiria a racionalidade humana e à qual se vinculariam todas as potencialidades humanas. Da razão destranscendentalizada e historicizada emerge a noção fraca de normatividade, desvinculando-a do sentido prescritivo forte que estava inerente à noção metafísica de formação humana. Com base na compreensão da condição humana como vulnerável e indeterminada e orientando-se por uma racionalidade procedimental e falibilista, o novo sentido de normatividade deve abrir mão da pretensão de querer prescrever, de modo vertical e definitivo, o conteúdo à ação humana.

Nessa perspectiva, o ideal de formação humana passa a ser compreendido como um processo aberto, cujo sentido é dado e Filosofia e Educação [RFE] - Volume 8, Número 2 - Campinas, SP Junho-Setembro de 2016 - ISSN 1984-9605 - p. 141-167 
permanentemente reconstruído pela participação dialógica de todos os concernidos. Ou seja, as pretensões de validade não podem ser mais indicadas de fora, verticalmente e alheias aos concernidos da comunidade de comunicação. O que fica claro, nesse contexto, é que as formas pósmetafísicas de pensamento não aceitam mais uma razão soberana e inquestionável, que de fora opera como indicadora de lugar, determinando previamente o sentido e a finalidade da formação humana.

Esse duplo esforço, por um lado, de justificar a ideia de formação humana com base no sentido fraco de normatividade e, por outro, de manter o diálogo vivo (crítico) com a tradição, também marca, em linhas gerais, o núcleo da argumentação desenvolvida por Pedro Goergen no ensaio "Formação ontem e hoje" (2009). Consciente da crescente pluralidade das formas contemporâneas de vida, ele argumenta sobre a necessidade de pensar as referências normativas, ou seja, de pensar as medidas e os padrões orientadores da formação humana, de modo não mais estático e absoluto, mas sim por meio de binômios tensionais como "'possibilidades e limites', 'egoidade e alteridade', 'permanência e mudança', 'identidade e diferença', 'transcendência e imanência', 'tradição e inovação"' (GOERGEN, 2009, p. 56). Ou seja, pela ótica do pensamento pós-metafísico, a ideia de formação humana passa a ser pensada pelo aspecto da mudança, diferença, imanência e inovação. Segundo Goergen, "Já não há um ‘telos' fixo e transcendente para o indivíduo e a sociedade: o homem deve assumir integralmente a responsabilidade por si mesmo" (2009, p. 58).

De outra parte, ele acentua outros traços que resultam da crítica à noção metafísica de formação humana: a) o caráter de sociabilidade e historicidade da condição humana; b) a subjetividade como constituída pela permanente tensão entre indivíduo e sociedade, entre individuação e socialização; c) o caráter histórico e indeterminado do devir humano. Esses três aspectos mostram, ao mesmo tempo, que a pretensão normativa do Filosofia e Educação [RFE] - Volume 8, Número 2 - Campinas, SP Junho-Setembro de 2016 - ISSN 1984-9605 - p. 141-167 
discurso humano não pode mais ser sustentada em sentido forte, pois não há como pretender algo absoluto e definitivo para o que é vulnerável e indeterminado. Desse contexto argumentativo mais amplo Goergen deriva o sentido democrático de formação humana. Ou seja, a historicização do devir humano e a reformulação em sentido fraco das pretensões normativas abrem a possibilidade para que a ideia de formação humana seja pensada como projeto individual e coletivo de natureza democrática e partilhada.

É justamente aí que percebemos o elo profundo entre políticas educacionais e filosofia da educação em sua análise: a noção democrática de poder sustenta-se numa concepção comunicativa de formação humana, do mesmo modo que tal formação só pode ser alcançada pela democratização das diferentes formas de gestão. Goergen arremata seu argumento do seguinte modo:

Essa ideia de argumentação, do entendimento no espaço público como estratégia instituinte do ideal formativo contemporâneo, coloca-nos diante da necessidade de repensar de uma maneira profunda e radical toda a educação contemporânea, tanto privada como pública (GOERGEN, 2009, p. 59).

Em outro ensaio, publicado no ano anterior, Goergen aborda mais detalhadamente a ideia de formação humana baseada no conceito comunicativo de razão. Inspirando-se em Habermas, ele concebe como problema de fundo a legitimidade das ações humanas e do próprio poder em um contexto cultural e político abertamente plural, resultado da globalização mundial e, com ela, a consequente desagregação dos Estados nacionais. Esse contexto exige uma nova forma de regulação política, a qual, orientada pelo ideal da cidadania democrática, somente pode se efetivar com a constituição da sociedade civil e do espaço público, ambos atuantes 
democraticamente. Com a tendência crescente da autorreferencialidade dos sistemas políticos, a sociedade civil possui o papel de "formular, em espaços públicos autônomos, os interesses e conflitos que se produzem na periferia do sistema institucionalizado, fazendo com que eles alcancem o sistema político" (GOERGEN, 2008, p. 51).

Essa confiança depositada na sociedade civil brota da crença de que ela é a sede da linguagem ordinária que detém o poder comunicativo capaz de tratar dos problemas gerais da sociedade. Ou seja, é do mundo da vida, e não da ordem sistêmica, que brota o potencial crítico e emancipatório inerente à linguagem humana. Ora, se tanto a sociedade civil como o espaço público são decisivos à democracia, Goergen considera a educação como indispensável para fortalecer esses espaços. Aos seus olhos, "parece inegável que é a educação (formal e informal) o principal mecanismo de formação do esclarecimento e do sentido crítico das pessoas" (GOERGEN, 2008, p. 69).

Mas esse sentido pós-metafísico de formação humana, pensado com forte inspiração na ideia habermasiana de razão comunicativa, significa uma despedida da tradição? De modo algum, pois o próprio Goergen mantém o diálogo vivo com a tradição. A título de ilustração, cabe referir seu confronto com o dialogo socrático realizado na parte inicial de seu ensaio (GOERGEN, 2009, p. 26-33), retendo três aspectos que, em certo sentido, também lhe servirão de referência para diagnosticar a situação atual do ensino superior.

O primeiro aspecto refere-se à educação como força propulsora da elevação moral e política da alma humana. Nessa perspectiva, já estava clara, para os gregos, a ideia de que a educação proporciona aquele polimento necessário ao ser humano, para que possa superar a rudeza selvagem que o habita. Principalmente no pensamento de Platão, destaca-se a ideia da educação moral do ser humano como força espiritual da Filosofia e Educação [RFE] - Volume 8, Número 2 - Campinas, SP Junho-Setembro de 2016 - ISSN 1984-9605 - p. 141-167 
transformação política e da reorganização do Estado. É essa base moral da educação, resgatada da paideia grega, que embasa, em certo sentido, o diagnóstico crítico de Goergen sobre a privatização e mercantilização do ensino superior atual, impulsionando-o a formular a tese da educação como um bem público. Sendo um valor humano intrínseco, pois é por meio dela que o homem, polindo-se, torna-se humano, a educação precisa ser tomada como um bem público, e não simplesmente como objeto de valor mercadológico. Nessa linha, o ideal educativo de formação do cidadão como "homem livre e emancipado, através da razão", ideal que, transformado pela classe burguesa dominante do início da modernidade, resultou em um homem submisso "à ordem burguesa e aos seus interesses, disposto a aceitar as regras do mercado [...]" (GOERGEN, 2001, p. 61), permanece mais vivo do que nunca.

O segundo aspecto repousa na ideia da formação integral como força orientadora do processo constante de melhoramento moral do ser humano, servindo a Goergen como fonte de inspiração crítica ao predomínio contemporâneo da educação profissionalizante. Nesse sentido, a maiêutica socrática, orientada pela pergunta irônica, visava a minar o senso comum que sustentava a educação especializada da época. A crítica socrática mostra-nos assim, instrutivamente, que o saber técnico precisa estar amparado na busca pela virtude e que a noção de um profissional bemsucedido depende da orientação de sua ação pelos ideais de virtude, destacando-se entre eles, os de justiça e temperança. Portanto, do ponto de vista moral, o profissional bem-sucedido é aquele que busca ser justo e temperante.

Por fim, o terceiro aspecto incide sobre o ideal socrático do permanente autoexame como condição do governo de si mesmo e do governo dos outros. Essa exigência posta por Sócrates a si mesmo e aos seus interlocutores serve amplamente de fonte de inspiração à democracia Filosofia e Educação [RFE] - Volume 8, Número 2 - Campinas, SP Junho-Setembro de 2016 - ISSN 1984-9605 - p. 141-167 
ocidental. Também serve de base, como não poderia ser diferente, à defesa firme que Goergen faz da gestão democrática como mecanismo de formulação das políticas públicas educacionais, com vistas a garantir a própria ideia de educação como um bem público. Nessa perspectiva, o fortalecimento de tal ideia depende do autoexame crítico de cada indivíduo, assegurado pelo espaço público de discussão.

\section{Considerações finais}

Educação como bem público, educação integral e educação como autoexame crítico, assegurado pelo espaço público de discussão. Eis três dimensões já encontradas no cerne da paideia grega, mas que, levando-se em conta o diagnóstico de época que Goergen faz do ensino superior, soam como urgentes e revestem-se de um novo sentido. Inspirando-se na noção habermasiana de razão comunicativa, Goergen defende a atualização moderna da Ágora antiga e, com ela, da própria reatualização da ideia de formação humana e, esforçando-se para desvencilhá-la de fortes pressuposições metafísicas, adota um sentido fraco de normatividade e uma concepção de razão destranscendentalizada e historicamente situada. Se isso, por um lado, torna o homem contemporâneo mais inseguro e vulnerável, por outro, protege-o de sua própria soberba e onipotência ilusória.

O esforço de Goergen em tomar o conceito de formação humana para discutir os rumos da educação superior, alicerçado num diagnóstico de época e na postura de crítica social, traduz o perfil de alguém que, a seu modo, retoma a tradição da paideia grega e o faz filiando-se a uma das mais importantes tradições de pensamento do Ocidente, a teoria social crítica contemporânea. Desse modo, tal esforço pode ser compreendido como um importante contributo em termos de pensar uma teoria crítica da educação 
no contexto de sociedades complexas e plurais. Nesse tocante, a Ágora contemporânea traduz o sentido de uma esfera pública. Trata-se, para utilizar as próprias palavras de nosso homenageado, e à guisa de conclusão, de

instituir o espaço público como o espaço vivo e permanente da instituição da formação contemporânea, arena essa na qual a única arma admitida será a palavra; a única estratégia, o argumento; e o único objetivo, o entendimento (2009, p. 58, grifo nosso).

\section{Referências}

APEL, K-O. Das Apriori der Kommunikationsgemeinschaft und die Grundlagen der Ethik. In: Transformation der Philosophie. Frankfurt am Main: Suhrkamp, 1999, (Bd.II).

ARENDT, H. Zwischen Vergangenheit und Zukunft. München: Piper, 1994.

BERNSTEIN, R. J. El abuso del mal. La corrupción de la política y la religión desde el 11-9. Buenos Aires: Katz, 2006.

BRANDT, R. Wozи noch Universitäten? Ein Essay. Hamburg: Meiner, 2011.

DE WIT, H. Internationalization of higher education in the United States of America and Europe: a historical, comparative, and conceptual analysis. Westport: Greenwood Press, 2002.

GOERGEN, P. L. Pós-modernidade, ética e educação. Campinas: Autores Associados, 2001.

Questões impertinentes para a Filosofia da Educação. Educação $e$ Pesquisa, v. 32, n. 3, 2006, p. 589-606.

Ação comunicativa, democracia e educação. In: SGRÓ, R. M. (org.). Teoría Crítica de la Sociedad, Educación, Democracia Y Ciudadanía. Tandil: UNCPBA, 2008. p. 33-72.

. Formação ontem e hoje. In: CENCI, A. V.; DALBOSCO, C. A.;

Filosofia e Educação [RFE] - Volume 8, Número 2 - Campinas, SP Junho-Setembro de 2016 - ISSN 1984-9605 - p. 141-167 
MÜHL, E. H. (orgs.). Sobre filosofia e educação: racionalidade, diversidade e formação pedagógica. Passo Fundo: Ed. Universidade de Passo Fundo, 2009. p. $25-63$.

Educação superior na perspectiva do sistema e do Plano Nacional de Educação. Educação \& Sociedade, v. 31, n. 112, 2010.

A internacionalização dos programas de pós-graduação. Revista Espaço Pedagógico, Passo Fundo, v. 19, n. 2, jul./ dez. 2012, p. 247-257. . Ciência, ética e sociedade. In: BOMBASSARO, L. C.; DALBOSCO, C. A.;

Hermann, N. A. Percursos hermenêticos e politicos: homenagem Hans-Georg Flickinger. Passo Fundo: Ed. Univeridade de Passo Fundo; Porto Alegre: EDIPUCRS; Caxias do Sul: Educs, 2014, p. 477-508.

GROS, F.; LÉVY, C. (orgs.). Foucault y la filosofía antigua. Buenos Aires: Nueva Visión, 2004.

HEIDEGGER, M. Voträge und Aufsätze. Stuttgart: Klett-Cotta, 2004.

NUSSBAUM, M. Sin fines de lucro. Por qué la democracia necesita de las humanidades. Buenos Aires: Katz Editores, 2010. 